\title{
Exploring Cohesions in EFL Academic Writing: A State of the Art on the Study of Cohesions
}

\author{
Orvi Banja Uru, Anselmus Sudirman and Andhi Dwi Nugroho \\ Universitas Sarjanawiyata Tamansiswa, Yogyakarta, Indonesia \\ anselmus.sudirman@gmail.com
}

\author{
ARTICLE HISTORY \\ Received : 6 May 2021 \\ Revised : 13 May 2021 \\ Accepted : 23 June 2021
}

\section{KEYWORDS}

Cohesion

Reference

Paired conjunction

Collocation

Reiteration

EFL academic writing

\begin{abstract}
Cohesion has become a crucial component of academic writing that promotes the semantic connection within phrases and sentences. The objectives of this literature review research are to identify different forms of cohesions and the most common form of cohesion in articles on EFL academic writing. This study extracted records from Google Scholar and Scopus databases and selected 20 studies in the last five years out of 700 on the use of cohesions in the writing of EFL students. The data was gathered by sorting similar messages, finding cohesions, clarifying cohesions, and counting the cohesions with the highest percentage. The research results show that the published articles containing cohesions represent the reference (35\%), paired conjunctions (15\%), reiteration (40\%), and collocation $(10 \%)$. The most common type of cohesion is reiteration, which is essential for comprehending what the authors mean in their published works. Cohesions in theoretical and practical grounds contribute to the explicitness of semantic components of words or phrases to generate the messages conveyed to readers.
\end{abstract}

\section{Introduction}

The link between components of phrases and sentences is the focus of most literature reviews on cohesions. To build cohesions, text elements attempt to indicate semantic links within and between phrases or sentences. Cohesions are also the surface marking of a semantic relationship between utterances, which includes the usage of substitution, ellipsis, reference, and conjunctions.

There have been few studies on cohesions in EFL academic writing, despite the importance of establishing cohesions at both the theoretical and practical levels. Students' ability to use cohesions is based on the semantic relationship between phrases and sentences. However, because of the intricacy of solutions necessary in mapping out EFL academic writing difficulties, the major issue in the practical use of cohesions is limited. Therefore, the goals of this literature review research are to deal with different types of cohesions and the most common type of cohesion in articles on EFL academic writing, in the hopes that students will be familiar with how to employ cohesions on a daily basis.

The use of cohesions allows people to quickly determine whether or not a group of phrases and sentences is closely linked. According to Halliday \& Hasan (2014), cohesion is a component of the language system that occurs in the semantic part of the text to clarify its meaning. To comprehend what is being said in the document, readers must first comprehend the word cohesion. The word "cohesion" is often used to describe the social context of a document. When writing, maintaining continuity is crucial. Cohesion is also a discourse analysis text that connects one word to the next to interpret a text's meaning. Cohesions in academic writing (Bowen \& Thomas, 2020) deal with complex choices that play a role in the unfolding of cohesiveness and knowledge flow, with precision and congruency being main contributors to texture creation while also exploiting context-dependency and complexity.

Linking words or phrases are important to consider during the writing process. In prose, the relationships between sentences must be organized using cohesive devices (Crossley, Kyle, \& McNamara, 2016; Farkas, 2016) to form a complete whole. In a paragraph, good writing should pay attention to the relationship between one sentence and the next. The writer must use the right words. Lexical elements (Simaki, Paradis, \& Kerren, 2019; Hilpert \& Correia Saavedra, 2017) and structures are required to construct the reference, link, or connection between each term. As a result, one of the most critical factors in improving writing quality is the consistency of meaning and type. Cohesion is a crucial component of good prose.

The sentences that a learner create, at least and especially in academic writing, must be explicit in order for readers to grasp the substance or context of each single sentence in the paragraphs that make up a text. Cohesion is one factor that can aid students in improving their writing abilities (Lock \& 
Saddler, 2004). The relation of meaning that occurs within a text is referred to as cohesion. Lexical cohesion and grammatical cohesion are the two forms of cohesion (Halliday \& Hasan, 2014). Reference, substitution, ellipsis, and conjunction are all examples of grammatical accuracy (Vickers, 2006). Reiteration and collocation are examples of lexical cohesion. Studying cohesion can assist students in producing a strong and structured text, as well as making and assisting readers in comprehending the information delivered by the writer in the text.

Cohesive devices help writers express an opinion from one sentence to the next, from one idea to the next, and from one paragraph to the next by using words or phrases. Cohesive devices bind the sentences and paragraphs together. Cohesive devices play an important role in students' comprehension of the writing process and genre knowledge (Wang \& Cho, 2010). The cohesive relationships within and between the sentences, which create texture, are the primary determinant factor of whether or not a set of sentences represent a text (Halliday \& Hasan, 2014). As a result, logical devices are needed to help the reader understand the writer's purpose. A text's structure, goals, and context are all intertwined. A written document's structure refers to how the content is organized. The reader can understand the text better if it is well structured. As a consequence, understanding how the sentences relate to one another is important.

As a result of the above issues, the researchers formulate the following research questions:

1. What are the different forms of cohesions in articles on EFL academic writing?

2. What is the most common type of cohesion in articles on EFL academic writing?

\section{Literature Review}

\subsection{English as a foreign language}

English is one of the compulsory subjects in Indonesian schools, and it is assessed in the national final exam. Despite the fact that it is a foreign language in situations where the people's first language is not English, but Indonesian or another regional language is often used in daily communications. Since the learners are not native English speakers, learning English can be challenging at times. Hence, EFL teachers should pay more attention to factors that affect autonomous learning, identity development, and a sense of agency in their students' learning processes (Yang, 2020).

On the other hand, it is because the pattern, structure, vocabularies, and even grammatical patterns of their language or mother tongue differ from those of English. They will begin writing in a number of contexts by using English as a foreign language. Writing is an effective means for them to communicate and share their feelings, opinions, and ideas.
The four essential skills in English teaching and learning as a foreign language are listening, reading, speaking, and writing. Writing, as one of the fourth language skills, is one of the most significant in EFL learners' lives. Besides, EFL students may use writing to advise others, conduct business, persuade, enrage, and communicate their emotions. Writing in a foreign language, on the other hand, is a daunting challenge. EFL teachers must be familiar with a wide range of linguistic and sociocultural contexts in order to anticipate some of their students' writing issues (Qin \& Uccelli, 2020). One of the four fundamental skills that they struggle with is EFL writing.

Writing in English as a foreign language is regarded as a crucial skill in both teaching and learning. Writing a portfolio, for example, is difficult for EFL students. Portfolio writing helps students improve their vocabulary, grammar, paper structure, and other skills, as well as composition, instructor feedback, and reflection (Saavedra-Jeldres \& Campos-Espinoza, 2019). In terms of portfolio writing, Farahian, Avarzamani, \& Rajabi (2021) found that while the experimental group's subscales of reflection, comprehension, and reflection improved, the procedure had no effect on EFL learners' critical reflection. The findings are discussed, as well as recommendations for incorporating portfolio writing into EFL classes to enable EFL writers to concentrate on their work. To begin with, EFL writing as such motivates them to think, organize their thoughts, and improve their ability to summarize, assess, and criticize. It enhances students' understanding of the English language, reasoning, and reflection.

\subsection{Academic Writing}

Academic writing is an important form of communication in everyday life, especially in high schools and colleges. Lin (2016) states that in English writing and teaching, EFL students continue to focus on the deconstruction of the model text and the relationship between reading and writing. According to Avarzamani \& Farahian (2019), EFL writers have a distinct lack of higherorder thought skills when writing, and are more involved in lower stages of reflection, such as repetitive actions and comprehension. Writing is an important medium for communicating and sharing feelings, thoughts, and ideas, regardless of certain challenges. EFL students use active forms to convey ideas or feelings, which they then turn into a symphony of words, such as expressing a writer's meaning to someone anticipated or readers. In tough times, it can be difficult for them to come up with writing ideas.

Academic writing is a challenging skill that must be mastered. Some students can communicate effectively in English but struggle to do so in writing. As a result, when writing, EFL students will collaborate to emphasize fluency and attitudes in focus, allowing them to substantially outperform the conventional community in terms of writing fluency (Hosseini, Bavali, \& Rezvani, 2020). Writing is described as a reflective task requiring sufficient time to think about a particular topic as well as evaluate and identify 
any prior knowledge. Writing is regarded as a complex practice, a social act that represents the writer's communicative skills, which are difficult to acquire and learn, especially in an EFL context. Writing is an essential skill for students to learn, they still struggle to master it. Because there are some differences between Indonesian and English, such as structural and grammatical terms and styles, mastering writing is difficult, particularly for EFL students in Indonesia (Ariyanti, 2016).

Zarrabi \& Bozorgian (2020) also note that in writing, it is typical for both the writer and the reader to have disagreements about how to view social and cultural influences. Additionally, students must be able to translate or convert meaning from Indonesian to English context in order for the writing to be legible and for the text to make sense when read by others, especially native speakers. Writing, on the other hand, is widely regarded as the most difficult language skill to master. As a result, teaching students how to create sentences correctly or write any English composition effectively becomes a top priority for English teachers. Learners must know and fully comprehend the aspects of grammatical errors in writing (Abushihab, 2014) or broad consistency in order to write well-ordered sentences.

Material, organization, vocabulary, language usage, and mechanics are the five main academic writing components (Klimova, 2011). The concept of content is linked to the concept of unity. Cohesion is linked to organization. Grammar and language use are related. The system is dealt with punctuation, and vocabulary is related to word selection. Learners can understand the role of each aspect used in English sentences until they have grasped the aspects. Even after spending years learning English, especially in writing, the students still struggle to express themselves in proper words or sentences. They sometimes make grammatical mistakes when constructing sentences or writing in English.

Students are unable to demonstrate critical thinking skills while writing, nor are researchers proposing ways to develop critical thinking skills among students. Teachers often discuss their students' critical thinking skills (or lack thereof) and how they affect classroom learning (Rahmat, et al., 2020). Other difficulties that writers face while academic writing include (a) linguistic difficulty (grammar, vocabulary, language use), (b) linguistic difficulty (grammar, vocabulary, language use), (c) linguistic difficulty (grammar, vocabulary, language use), (d) linguistic difficulty (grammar, vocabulary, language use), (d) linguistic (b) difficulty with physiology (no contact between writer and reader), and (c) problems of the mind (punctuation, capitalization, and paragraphing).

Some authors are labeled as "bad" because their language skills (Dollmann \& Rudolphi, 2020; Thunberg, 2019) should be sharpened as soon as they arrive at universities; they lack the ability to apply what they have learned. The nature of the overall classroom background influences students' language skills, and the composition of friendship networks within school classes is worth considering.

The praxis of academic writing is the most important tool for improving students' writing skills and resolving writing problems as previously mentioned. As a result, it is vital for students to learn principles, promote academic writing, and enrich the culture of academic writing (Toprak \& Yücel, 2020).

\subsection{Cohesion}

Cohesion is one factor that can aid students in improving their writing abilities. Cohesion is a semantic property of a text that allows it to bind in some way. In academic writing, cohesion is often a key component. Semantically, a coherent text appears to connect its sentences as one. The term "cohesion" refers to the relationship between forms. This implies that the elements of words or sentences used to create a text are relevant and intact. Cohesion is a form of language surface building that can be seen in both vocabulary and grammar (Baldwin, 2014). It is hard to say what a text is when you are writing it. It implies that a text is more than just a sentence; it has a structure that can be interpreted in a systematic way.

Cohesion is a crucial component of a good prose. The sentences that a learner create must be explicit in order for readers to grasp the substance or context of each single sentence in the paragraphs that make up a text. As Halliday \& Hasan (2014) put, cohesion is a component of the language system that occurs in the semantic part of the text to clarify its meaning. A text or essay is a set of paragraphs that are made up of one element in the text that must state the interrelated concept, rather than a series of sentences with each sentence containing a different subject.

Ampa \& Dalle (2019) outline that cohesion is the relationship between parts in a text that is characterized by the use of language elements. Cohesion is described as the relationship between the elements of language, as stated above. All of the components of terms and sentences are included here. For example, to be a phrase, we need morphemes, prefixes, suffixes, and other elements. Then, an expression, a clause, or a sentence can be made out of a group of words, and writers will need all of them to create a document.

Cohesion refers to how words and sections of a text are linked together through the use of devices such as conjunctions, references, substitutions, ellipsis, and lexical cohesion (Halliday \& Hasan, 2014). The semantic connections or relationships of meanings that occur within the text and characterize it as a text are referred to as cohesion in the text. It will encourage students to do well in their writing. Furthermore, Karjono (2019) adds that cohesion refers to the degree to which a sentence or even separate sections of a single sentence are related in such a way that the flow of ideas is easy to follow. Cohesive devices are also critical for achieving good cohesion. 
Cohesion is divided into two groups by (Halliday \& Hasan, 2014): grammatical cohesion and lexical cohesion. Grammatical cohesion is a grammatical relationship. The use of grammatical elements of the texts to convey the semantic relationships inside and between sentences creates grammatical cohesion (Klimova \& Hubackova, 2014; Ampa \& Dalle, 2019). In written discourse, grammatical cohesion is the surface marking of a semantic connection between clauses and sentences; in speech, it is the surface marking of a semantic link between utterances and turns. Reference, substitution, ellipsis, and conjunction are all subcategories of grammatical cohesion.

\subsection{Reference}

A reference is unique information that connects two words. Sudirman \& Tiasari (2017) examine that referencing in a written text refers to how the author introduces and keeps track of participants in the text. Referencing in writing demonstrates how the writer introduces the participants and keeps track of them in the document. Thus, the role of reference, particularly in writing, is to refer to participants without mentioning their names, but rather by referring to them with another word that still has a connection or link. There are three types of references: pronoun, demonstrative, and comparative.

I, you, they, she, and he are examples of pronoun references. When referring to a single participant, demonstrative reference is used. This, these, that, those, and there are examples of demonstrative references. Similar, more, and most are examples of comparative references. Comparative comparison is conveyed by adjectives and adverbs and is used to compare objects in a text in terms of identity or resemblance (Syam, 2018). The indirect comparison by means of identification or resemblance is referred to as comparative reference.

Michael, Muthusamy, Suppiah, Joseph, \& Razali (2013) also define three forms of referencing: homophoric referencing, which refers to information that is transmitted across cultures, exophoric referencing, which refers to information that is obtained directly from the circumstances, and endophoric referencing, which refers to information that is 'retrieved' from within the document. Anaphoric, cataphoric, and esophoric referencing are the three types of endophoric referencing. Any reference that 'points backward' to prior knowledge in the text is anaphoric. Any reference that 'points forward' to knowledge that is mentioned later in the text is referred to as cataphoric. Any relation to the same small group of phrases that follows the presupposed item is esophoric.

Personal references, demonstrative references, and comparative references are the three major forms of references (Halliday \& Hasan, 2014). The categories of personal reference include: 1) personal pronouns: I, You, They, We, He, She, It, Her, Us, Them. 2) possessive determiners: My, Yours, Their, Its, Our, His and Her. 3) possessive pronouns: Mine, Yours, Hers, Theirs, Ours. There are three types of demonstrative reference: nominative demonstrative: this, that, these, and others. Here, there, now, then, and definite article are examples of circumstantial demonstratives (the). Comparative relation is divided into two types: general and specific comparison. General comparison refers to comparisons that are made solely on the basis of likeness and unlikeness, without regard to any specific property: two things may be the same, similar, or different (the term "different" encompasses both "not the same" and "not similar").

\subsection{Substitution}

Substitution is the process of replacing a word, expression, or entire clause with another to prevent repetition. It is used to swap out one object for another without having to repeat the process. Priyatmojo (2012) defines substitution as the process of replacing a word (group) or a sentence section with a dummy word. Substitution and references are two distinct concepts. The distinction between substitution and reference is that substitution is concerned with the relationship between terms, while reference is concerned with the relationship between meanings (Bahaziq, 2016). Furthermore, Halliday \& Hasan (2014) argue that substitution is a "wording relationship" rather than a "sense relationship". Nominal substitution, verbal substitution, and clausal substitution are the three types of substitution. One, ones, and the same are examples of nominal substitution. Do, did, and another auxiliary verb are examples of verbal substitution. Clausal substitution, for example; thus, not.

\subsection{Ellipsis}

Ellipsis is the process of replacing a phrase with nothing or omitting language units to remove lexical repetition. Ellipsis is the absence of linguistic components. Normally, it is needed by grammar, which the writer assumes is obvious from the context, and therefore it is unnecessary to increase. Nominal ellipsis, verbal ellipsis, and clausal ellipsis are the three forms of ellipsis. An ellipsis, according to Priyatmojo (2012), is the absence of a word or a portion of a sentence. It happens when certain crucial structural elements are missing from a sentence or clause and can only be recovered by referring to a previous text element. Bahaziq (2016) explains that the noun is omitted in nominal ellipsis. The omission of the verb is known as verbal ellipsis. When a clause is omitted, clausal ellipsis occurs. Ellipsis is the omission of grammar-required elements that the speaker or writer believes are obvious from the context and therefore do not need to be raised (Syam, 2018). It implies that if any structural elements are missing from a sentence, the referring element to the text will recover them.

\subsection{Conjunction}

The conjunction is commonly used in paragraph writing to establish an explicit relation between sentences in order to produce coherence. A conjunction is a word or phrase that acts as a connection between terms, phrases, clauses, 
sentences, and paragraphs. A conjunction is a relationship that indicates how the next sentence or clause should be connected to the previous or subsequent parts of the sentence. Conjunction is a semantic relation that communicates how one clause or sentence relates to another in terms of meaning; it is indicated by a particular reference word or expression (Syam, 2018). When deciding the conjunctions to use, students must go through a thorough thought process to ensure that the logic of the arguments is improved rather than hindered by the use of these linking devices, as is often the case. Instead of the regular lists of conjunctions, carefully devised exercises may aid in the development of this critical thinking method and the expansion of their arsenal of these devices. This will be the best way for language learners to improve their overall proficiency (Martínez, 2015).

The four forms of conjunction (Halliday \& Hasan, 2014) are additive conjunction, adversative conjunction, causal conjunction, and temporal conjunction. Also, and, too, furthermore, additionally, etc. are examples of additive conjunctions that structurally coordinate by combining to the presupposed object. Neither nor, either or, etc. are examples of additive conjunctions that are used to counteract the presupposed object. Adversative conjunction functions, which are indicated by the use of; in reality, however, just, yet, but, rather, etc., are used to display 'contrary to expectation.' The use of so, then, for, since, for this reason, as a consequence, in this regard, etc., indicates a causal conjunction that conveys 'result, reason, and purposes.' The conjunctive category is sequential, and it links things by implying a sequence or a period of time. The words then, next, after that, the next day, at this moment, and so on are examples of sequential conjunctive signals.

\subsection{Lexical Cohesion}

Lexical cohesion is the connection between the various sections of a text in order to achieve a unified structure. Lexical continuity has to do with the text's context. Lexical cohesion isn't a grammatical concept. The cohesive effect achieved by the choice of vocabulary is referred to as lexical cohesion. As a result, it is concerned with the relation based on the words used rather than the grammatical and semantic connections. Bahaziq (2016) points out that lexical cohesion entails vocabulary selection. It is concerned with the relationship between lexical objects such as words and phrases in a text. Reiteration and collocation are two forms of lexical cohesion (Halliday \& Hasan, 2014). The writer's use of lexical objects such as verbs, adjectives, nouns, and adverbs to contribute to the text faithfully to its area of emphasis is referred to as lexical cohesion. It is suggested that lexical elements/vocabularies be used. Reiteration and collocation are two of the groups.

\subsection{Reiteration}

Reiteration is a method for creating continuity in a text by repeating two or more lexical items visible at the text's surface. The four parts of lexical continuity in reiteration are repetition, synonymy, near-synonymy, superordinate, and general terms. When a lexical item or a word element is repeated in a sentence, it is called repetition. A synonym is a word equivalence that establishes a corresponding meaning relationship between one lingual unit and other lingual units in a text. Words with words, phrases with phrases, phrases with phrases, and sentences with sentences may all form synonym relationships. Furthermore, Syam (2018) accentuates that a synonym is a term with a similar meaning. Near-synonymy refers to a lexical object that is similar but not identical. When the meaning of the lexical object (discussed later) dominates the meaning of the other item, superordinate is used (mentioned earlier).

\subsection{Collocation}

The regular pattern of relationship between words is known as collocation. Collocation is accomplished by linking lexical objects that often occur together. It refers to lexical elements that are likely to be found in the same lexical environment. A collocation is a grouping of two or more words in English that are often used together. The term "collocation" refers to lexical objects that were most likely discovered together in the same text. Collocation occurs when two words are not essentially based on an indistinguishable semantic relation but are inclined to occur in the same lexical environment to some degree. Hyponymy, antonymy, and meronymy are examples of collocation in context (Brezina, McEnery, \& Wattam, 2015).

\section{Method}

The researchers used a literature review approach to gather information. A literature review is an excellent way of synthesizing research results to show evidence on a metalevel and to identify areas where further research is required, which is an important part of developing theoretical frameworks and conceptual models (Snyder, 2019).

The research articles on EFL students' use of cohesion came from Google Scholar and Scopus databases. Types of cohesions, EFL writing, reference, conjunction, collocation, and reiteration were among the keywords used when looking for information about cohesions. The total number of articles was 700. Articles discussing types of cohesions involving references, conjunctions, colocations, and reiteration meet the inclusion criteria. Articles were published in the area of EFL academic writing from 2015 to 2020.

Articles that did not examine cohesion in the context of EFL academic writing were excluded, as were those whose publication years were older than those of the articles included. The researchers chose 20 articles to analyze based on the study's inclusion criteria since each published article was carefully chosen and investigated in terms of the use of cohesions. The data was analyzed using cohesion theories (Halliday \& Hasan, 2014; Bahaziq, 2016; Klimova \& Hubackova, 2014; Ampa \& Dalle, 2019). The researchers wrote a report based on the data analysis, and the use of 
cohesions was counted to determine the high frequency of cohesions used.

\section{Results \& Discussion}

The researchers examined a number of publications that included a wide range of cohesive devices. Dania's research (2018) shows that cohesive devices are important devices to create cohesive abstracts, namely reference, substitution, ellipsis, and conjunction. The term "cohesive devices" was used 190 times. Conjunctions, which appear 395 times, are the most frequently encountered cohesive device, followed by references, which appear 156 times. There were 37 instances of lexical cohesion, but only two instances of substitution. Thus, cohesive devices are essential for the development of cohesive abstracts (Dania, 2018). To make the abstract understandable to readers, students must use more acceptable cohesive devices.

In what follows, Syam's research (2018) examines the use of the third-person pronouns she and he by the protagonist of the Rapunzel fairy tale. There were 64 additive conjunctions and 10 comparative conjunctions in the sentences, while neither...nor, or, and if were only used once. The writer only uses the phrases "may" and "hair" twice. "Grief," "misery," "saw," and "listen" are synonyms for "animal," and the writer uses the terms "bird" and "cat," which are hyponyms for "animal." In relation to this finding, González (2010) once explored the use of continuity to highlight the flow of ideas in paragraphs using conjunctions appropriately.

Wandira's research (2020) demonstrates that in Malin Kundang's narrative text, there are two types of lexical cohesion: reiteration and collocation. According to the researcher, there are 70 instances of repetition, 21 antonymy, 19 metonymy, 13 hyponymy, and 6 synonymy. As a result, the author frequently employs repetition as a lexical continuity strategy. Bahaziq (2016) emphasizes the importance of using coherent devices while writing. When the elements of a text are linked and considered meaningful to the reader, it is said to be cohesive. These relations could be grammatical or lexical in nature. Based on the review, a reference is used in 71.08 percent of the grammatical devices used in the article. Conjunction and ellipsis account for the remaining 28.92 percent of total grammatical devices used in the text. There are no alternatives. In addition, the students use the lexical system reiteration but never collocation.

A study on cohesions by Sudirman \& Tiasari (2017) shows that the most frequently used category in undergraduate theses is order (26 percent), followed by significance (24 percent), connecting or transfer terms (20 percent), keyword repetition (18 percent), and the use of reference words (18 percent). When it comes to the students' perceptions of how to produce good writing quality, Saputra \& Hakim (2020) find that using linkages or coherent strategies to establish coherence in writing is essential. Students will be able to connect the concepts in a text by utilizing more cohesive devices in their writings, displaying their ability to compose effective pieces of writing employing references, conjunctions, duplications, and synonyms.

Afrianto (2017) asserts that if students misuse coherent instruments, the text's meaning will be lost, and the semantic relationship will be broken. Finally, the document would be incoherent. The sense of the text would be difficult for readers to grasp. Furthermore, Afrianto (2017) demonstrates that, after analyzing three essays, the researcher discovers that comparison is the most commonly used.

The researchers found 33 instances of personal reference, 1 instance of demonstrative reference, 6 instances of additive conjunction, 4 instances of adversative conjunction, 4 instances of temporal conjunction, and 5 instances of causal conjunction in text 1 . The researchers found 7 examples of personal reference, 6 instances of demonstrative reference, 5 cases of additive conjunction, 6 instances of temporal conjunction, 3 instances of causal conjunction, 1 instance of verbal replacement, and 1 example of nominal ellipsis in text 2. The researchers discovered 24 incidents of personal reference, 5 instances of demonstrative reference, 5 incidents of additive conjunction, 2 instances of adversative conjunction, 3 instances of temporal conjunction, 2 instances of causal conjunction, and 1 instance of verbal replacement in text.

Table 1. Types of cohesions in EFL academic writing based on the article reviews

\begin{tabular}{lclc}
\hline Types of Cohesions & Number of Articles & \multicolumn{1}{c}{ References } & Percentages \\
\hline Reference & 7 & Bahaziq (2016), Saputra \& Hakim (2020), & $35 \%$ \\
& 3 & Afrianto (2017), Dania (2018). & $15 \%$ \\
Paired conjunction & 8 & Syam (2018), (Ismail \& Linda, 2018) & $40 \%$ \\
Reiteration & & Ampa \& Basri (2019), Malah (2015), & (Wandira, 2020), (Kadiri, Igbokwe, \\
& 2 & Okebalama, \& Egbe, 2016) & $10 \%$ \\
Collocation & 20 & Sudirman \& Tiasari (2017), & $100 \%$ \\
\hline \multicolumn{1}{c}{ Total } & & &
\end{tabular}


Table 1 shows that reiteration is the most frequently appeared cohesion $(40 \%)$ as reflected through the studies undertaken by Ampa \& Basri (2019), Malah (2015), Wandira (2020), Kadiri, Igbokwe, Okebalama, \& Egbe (2016). This fact indictaes the reiteration is a technique for bringing a passage together by repeating one or more lexical units that are visible on the surface. The four parts of reiteration are repetition, synonymy, near-synonymy, superordinate, and general terms. Reference is in the second rank of cohesion used in several studies by Bahaziq (2016), Saputra \& Hakim (2020), Afrianto (2017), and Dania (2018). In a written text, reference describes how the writer introduces participants and keeps track of them throughout the text. The use of reference demonstrates how the author introduces the participants and keeps track of them throughout the text. In investigations conducted by Syam (2018), Ismail \& Linda (2018), the use of paired conjunctions appears three times. This denotes the difficulty of a paired conjunction, which connects two parts of similar grammatical and syntactic importance. Two separate clauses are linked by paired conjunctions. Meanwhile, in Sudirman \& Tiasari's research (2017), collocation only happens twice $(10 \%)$ in a regular pattern of word relationships, implying that collocation is the least usage of cohesion. Collocation is performed by associating lexical objects that frequently cooccur based on semantic and lexical relationships that are indistinguishable. Hyponymy, antonymy, and meronymy are examples of collocation.

There are two types of cohesion (Halliday \& Hasan, 2014): (1) grammar cohesion, such as reference, which includes demonstrative, personal, and comparative reference. Nominal ellipsis, verbal ellipsis, and clausal ellipsis are all forms of ellipsis. Additive conjunction, adversative conjunction, and causal conjunction are the three types of conjunction. Nominal substitution, verbal substitution, and clausal substitution are the three types of substitution. (2) lexical continuity, which includes repetition, synonymy, near-synonymy, and superordinate, as well as reiteration. Collocation includes hyponymy, antonymy, and meronymy.

\section{Conclusion}

By demonstrating the state of the art on cohesions, this systematic literature review contributed to filling the research gap of components of phrases and sentences, which is the main emphasis of most literature reviews in EFL academic writing. The complexity of academic writing problems calls for solutions that take into account the most common practical uses of cohesions in an EFL writing context. As a result, this literature review research explores numerous sorts of cohesions in EFL academic writing articles, as well as the most common type of cohesion.

The researchers analyzed the data using Halliday \& Hasan's (2014) approach, which separates the cohesion category into two components, grammatical and lexical cohesion, with reference (35\%), paired conjunction (15\%), reiteration $(40 \%)$, and collocation $(10 \%)$ as the four aspects of grammatical cohesion. The most common type of cohesion is reiteration, which means that relevant articles in this research frequently employ synonymy, repetition, nearsynonymy, generic terms, and superordinate to repeat numerous lexical units in a passage.

If students wish to reduce the number of errors in their sentences, they must first understand cohesion, what it is, and how to use it in their writing to produce a meaningful phrase or text. It is impossible to overestimate the significance of cohesion in phrases and sentences. Linkages between phrases must be structured consistently to maintain a sense of continuity in writing. The relationship between one statement and the next should be the focal point of good paragraph writing. A writer must explore lexical elements and structures as well as proper cohesions to establish the reference, link, or connection between each word in a sentence or text. One of the most important parts of writing quality and improvement is consistency in the use of cohesions to express meaning. Furthermore, this study suggests that writing instructors can incorporate critical thinking skills while making decisions about the article's content, utility, and fit within the writer's needs.

\section{References}

Abushihab, I. (2014). An Analysis of Grammatical Errors in Writing Made by Turkish Learners of English as a Foreign Language. International Journal of Linguistics, 6(4), 213. https://doi.org/10.5296/ijl.v6i4.6190

Afrianto, A. (2017). Grammatical Cohesion in Students' Writing: a Case At Universitas Teknokrat Indonesia. LEKSEMA: Jurnal Bahasa Dan Sastra, 2(2), 97. https://doi.org/10.22515/ljbs.v2i2.899

Ampa, A. T., \& Dalle, M. B. (2019). Lexical and Grammatical Cohesions in the Students' Essay Writing as the English Productive skills. Journal of Physics: Conference Series, 1339, 012072. https://doi.org/10.1088/1742-6596/1339/1/012072

Ariyanti, A. (2016). The Teaching of EFL Writing in Indonesia. Dinamika Ilmu, 16(2), 263. https://doi.org/10.21093/di.v16i2.274

Avarzamani, F., \& Farahian, M. (2019). An investigation into EFL learners' reflection in writing and the inhibitors to their reflection. Cogent Psychology, 6(1), 1690817.

https://doi.org/10.1080/23311908.2019.1690817

Bahaziq, A. (2016). Cohesive Devices in Written Discourse: A Discourse Analysis of a Student's Essay Writing. English Language Teaching, 9(7), 112. https://doi.org/10.5539/elt.v9n7p112

Baldwin, E. R. (2014). Beyond Constrictive Rhetoric: Helping International Lawyers Use Cohesive Devices in U.S. Legal Writing, 26 Fla. Florida Journal of International Law, 26, 399. 
Bowen, N. E. J. A., \& Thomas, N. (2020). Manipulating texture and cohesion in academic writing: A keystroke logging study. Journal of Second Language Writing, 50 , 100773. https://doi.org/10.1016/j.jslw.2020.100773

Brezina, V., McEnery, T., \& Wattam, S. (2015). Collocations in context. International Journal of Corpus Linguistics, 20(2), 139-173. https://doi.org/10.1075/ijcl.20.2.01bre

Crossley, S. A., Kyle, K., \& McNamara, D. S. (2016). The development and use of cohesive devices in L2 writing and their relations to judgments of essay quality. Journal of Second Language Writing, 32, 1-16. https://doi.org/10.1016/j.jslw.2016.01.003

Dania, R. (2018). Cohesion in The Abstract of The Theses Written by Undergraduate Students of English Education Program. Tell-Us Journal, 4(2), 141-157. https://doi.org/10.22202/tus.2018.v4i2.2844

Dollmann, J., \& Rudolphi, F. (2020). Classroom composition and language skills: the role of school class and friend characteristics. British Journal of Sociology of Education, 41(8), 1200-1217. https://doi.org/10.1080/01425692.2020.1799754

Farkas, A. (2016). Organized Chaos: Cohesive Devices in Benjy's Sections of William Faulkner's The Sound and the Fury. Acta Universitatis Sapientiae, Philologica, 8(2), 167-176. https://doi.org/10.1515/ausp-2016-0025

Gómez González, M. de los Á. (2010). Evaluating lexical cohesion in telephone conversations. Discourse Studies, 12(5), 599-623. https://doi.org/10.1177/1461445610371052

Halliday, M. A. K., \& Hasan, K. (2014). Cohesion in English. Cohesion in English. https://doi.org/10.4324/9781315836010

Hanim Rahmat, N., Aripin, N., Maizura Lin, N., Whanchit, W., \& Khairuddin, Z. (2020). Exploring the Connection between Critical Thinking Skills and Academic Writing. International Journal of Asian Social Science, 10(2), 118-128. https://doi.org/10.18488/journal.1.2020.102.118.128

Hilpert, M., \& Correia Saavedra, D. (2017). Why are grammatical elements more evenly dispersed than lexical elements? Assessing the roles of text frequency and semantic generality. Corpora, 12(3), 369-392. https://doi.org/10.3366/cor.2017.0125

Hosseini, M. S., Bavali, M., \& Rezvani, R. (2020). Wikibased collaborative writing in EFL classrooms: Fluency and learners' attitudes in focus. Cogent Arts \& Humanities, $7(1), \quad 1826649$. https://doi.org/10.1080/23311983.2020.1826649

Karjono, S. (2019). The Indonesian Undergraduate Students'
Competence in Writing Introduction of Thesis Proposals: A Discourse Analysis. Journal of English Language and Pedagogy, 1(2), 1-21. https://doi.org/10.36597/jelp.v1i2.4119

Klimova, B. F. (2011). Evaluating writing in english as a second language. Procedia - Social and Behavioral Sciences, 28, 390-394. https://doi.org/10.1016/j.sbspro.2011.11.074

Klimova, B. F., \& Hubackova, S. (2014). Grammatical Cohesion in Abstracts. Procedia - Social and Behavioral Sciences, 116, 664-668. https://doi.org/10.1016/j.sbspro.2014.01.276

Lin, Z. (2016). Context-model-based instruction in teaching EFL writing: A narrative inquiry. Cogent Education, $3(1)$, 1154258 . https://doi.org/10.1080/2331186X.2016.1154258

Lock, R. H., \& Saddler, B. (2004). Improve Writing Ability. Intervention in School and Clinic, 39(5), 310-314. https://doi.org/10.1177/10534512040390050901

Martínez, A. C. L. (2015). Use of Conjunctions in the Compositions of Secondary Education Students. Procedia - Social and Behavioral Sciences, 212, 4246. https://doi.org/10.1016/j.sbspro.2015.11.296

Michael, A. S., Muthusamy, C., Suppiah, P. C., Joseph, C., \& Razali, S. M. B. C. (2013). Cohesion in news articles: A discourse analysis approach. International Journal of Applied Linguistics and English Literature, 2(3), https://doi.org/10.7575/aiac.ijalel.v.2n.3p.129

129-133.

Mirzapour, F., \& Ahmadi, M. (2011). Study on Lexical Cohesion in English and Persian Research Articles (A Comparative Study). English Language Teaching, 4(4), 245-253. https://doi.org/10.5539/elt.v4n4p245

Priyatmojo, A. S. (2012). Improving Cohesion of the Studentsâ $€^{\mathrm{TM}}$ Sentences Through the Application of Cohesion Theory in the Sentence-Based Writing Class. Language Circle: Journal of Language and Literature, 6(2), 71-81. https://doi.org/10.15294/lc.v6i2.2409

Qin, W., \& Uccelli, P. (2020). Beyond linguistic complexity: Assessing register flexibility in EFL writing across contexts. Assessing Writing, 45, 100465. https://doi.org/10.1016/j.asw.2020.100465

Saavedra-Jeldres, P. A., \& Campos-Espinoza, M. (2019). Chilean Pre-Service Teachers' Perceptions Towards Benefits and Challenges of EFL Writing Portfolios. Profile: Issues in Teachers' Professional Development, 21(2), 79-96. https://doi.org/10.15446/profile.v21n2.73116

Saputra, A., \& Hakim, M. A. R. (2020). The Usage of Cohesive Devices by High-Achieving EFL Students in Writing Argumentative Essays. Indonesian TESOL 
Journal, 2(1), 42-58. https://doi.org/10.24256/itj.v2i1.1227

Simaki, V., Paradis, C., \& Kerren, A. (2019). A two-step procedure to identify lexical elements of stance constructions in discourse from political blogs. Corpora, 14(3), 379-405. https://doi.org/10.3366/cor.2019.0179

Snyder, H. (2019). Literature review as a research methodology: An overview and guidelines. Journal of Business Research, 104(July), 333-339. https://doi.org/10.1016/j.jbusres.2019.07.039

Sudirman, A., \& Tiasari, L. (2017). Cohesion in Undergraduate Theses: A Discourse Analysis. International Journal of Science and Research (IJSR), $6(11)$, 1851-1856. https://doi.org/10.21275/ART20178166

Syam, A. T. (2018). [RETRACTED] A Discourse Analysis of German Fairy Tale "Rapunzel" Written by the Brothers Grimm. Ethical Lingua: Journal of Language Teaching and Literature, 5(2), 219. https://doi.org/10.30605/ethicallingua.v5i2.1037

Thunberg, S. (2019). Ideas in action: some reflections concerning teaching language skills to social work students. Social Work Education, 38(2), 282-286. https://doi.org/10.1080/02615479.2018.1515312

Toprak, Z., \& Yücel, V. (2020). A peculiar practice of academic writing: Epidemic writing in the Turkish graduate education. Cogent Education, 7(1), 1774098. https://doi.org/10.1080/2331186X.2020.1774098

Vickers, C. H. (2006). Grammatical accuracy and learner autonomy in advanced writing. ELT Journal, 60(2), 109-116. https://doi.org/10.1093/elt/cci097

Wandira, S. (2020). The Characteristics of Cohesion in Malin Kundang Narrative Text, 7(January), 157-175.

Wang, X., \& Cho, K. (2010). Computational Linguistic Assessment of Genre Differences Focusing on Text Cohesive Devices of Student Writing: Implications for Library Instruction. The Journal of Academic Librarianship, 36(6), 501-510. https://doi.org/10.1016/j.acalib.2010.08.006

Yang, K. (2020). Autonomy, agency, and identity in teaching and learning English as a foreign language. Journal of Education for Teaching, 46(2), 251-253. https://doi.org/10.1080/02607476.2020.1712913

Zarrabi, F., \& Bozorgian, H. (2020). EFL Students' Cognitive Performance during Argumentative Essay Writing: A log-file data analysis. Computers and Composition, $\quad 55, \quad 102546$. https://doi.org/10.1016/j.compcom.2020.102546 